\title{
JANELAS PARA A PERCEPÇÃO INFANTIL DE AMBIENTES NATURAIS ${ }^{1}$
}

\author{
Christiana Cabicieri Profice ${ }^{2}$ \\ Universidade Estadual de Santa Cruz, Ilhéus-BA, Brasil \\ José de Queiroz Pinheiro \\ Universidade Federal do Rio Grande do Norte, Natal-RN, Brasil \\ Ana Cláudia Fandi \\ Ana Roberta Gomes \\ Instituto de Estudos Socioambientais do Sul da Bahia, Ilhéus-BA, Brasil
}

\begin{abstract}
RESUMO. Apresentamos um panorama das pesquisas recentes que utilizam o desenho como ferramenta metodológica para investigar a percepção das crianças sobre os ambientes naturais. Destacamos seus principais pressupostos e achados, buscando estabelecer um diálogo com nossa própria investigação. Nosso estudo, de caráter exploratório e descritivo, trata da percepção de crianças sobre ambientes naturais protegidos. Foi realizado com um grupo de 209 crianças de seis a onze anos de idade, em uma área de Mata Atlântica no Sul da Bahia. Debatemos a pertinência do uso do desenho e apontamos também suas limitações, argumentando em favor de uma abordagem multimetodológica. Pontuamos os principais achados e reflexões de nossa pesquisa, indicando questões que julgamos pertinentes para futuras pesquisas que usem o desenho para acessar a percepção de crianças sobre os ambientes naturais.
\end{abstract}

Palavras-chave: Crianças; desenhos; meio ambiente.

\section{DRAWN LANDSCAPES: WINDOWS FOR CHILDREN'S PERCEPTION OF NATURAL ENVIRONMENTS}

ABSTRACT. We present a panorama of the recent literature that uses the drawing as methodological tool to investigate children's perception of natural environments. We discuss their main assumptions and findings, searching to establish a dialogue with our own inquiry. We describe our exploratory and descriptive research with 209 children, aged six to eleven, in a Rain Forest context in Bahia, Brazil. We discuss the relevance of the use of the drawings and also point its limitations, arguing for a multimethod approach. After discussing our findings we indicate relevant issues for future studies that choose drawings to access children's perceptions of natural environments.

Key words: Children; drawings; environment.

\section{PAISAJES DIBUJADOS - VENTANAS PARA LA PERCEPCIÓN INFANTIL DE AMBIENTES NATURALES}

RESUMEN. Presentamos un panorama de las investigaciones recientes que utilizan el dibujo como herramienta metodológica para investigar la percepción que los niños tienen de los ambientes naturales. Señalamos sus principales presupuestos y hallazgos, buscando establecer un diálogo con nuestra propia investigación. Describimos nuestra investigación exploratoria y descriptiva sobre la percepción ambiental infantil de ambientes naturales protegidos, realizada con un grupo de 209 niños de seis a once años, en un área de Mata Atlántica en el sur de Bahía, Brasil. Discutimos la importancia del uso del dibujo y también señalamos sus limitaciones, argumentando en favor de un abordaje multimétodos. Evidenciamos los principales hallazgos y reflexiones de nuestra investigación indicando cuestiones que juzgamos pertinentes para futuras investigaciones que usen el dibujo para acceder la percepción que niños tienen de los ambientes naturales

Palabras-clave: Niños; dibujos; medio ambiente.

1 Apoio e financiamento: Fundação de Apoio à Pesquisa do Estado da Bahia (FAPESB) e Instituto de Estudos Socioambientais da Bahia (IESB).

2 Endereço para correspondência: Universidade Estadual de Santa Cruz - Departamento de Filosofia e Ciências Humanas, Rodovia Ilhéus-Itabuna, Km 15 - Salobrinho - CEP 45.650-000 - Ilhéus-BA. E-mail: ccprofice@uesc.br 
Um dos desafios ambientais de nossa época consiste na preservação da biodiversidade e dos ecossistemas naturais que viabilizam sua existência. Nos últimos cem anos os ambientes naturais vêm sendo substituídos por comunidades urbanas em um ritmo crescente. Recentemente atingimos a marca de sete bilhões de habitantes no planeta, e em nosso país $87 \%$ da população vivem em áreas urbanas (UNFPA, 2011). Diante deste cenário de afastamento das pessoas dos ambientes naturais surge a necessidade de mobilizar as novas gerações para a sua valorização e preservação. Nesta direção, a percepção das crianças sobre ambientes naturais tem sido objeto de estudos que visam subsidiar propostas em educação ambiental. É consenso que medidas precisam ser tomadas para que esta separação entre crianças e ambientes naturais não seja irremediável levando em consideração a percepção e a preferência ambiental das crianças (Arbogast, Kane, Kirwan \& Hertel, 2009; Chawla; 2002, Kahan, 2002; Kellert, 2002). Uma parcela significativa destas investigações utiliza o desenho como forma de acesso às percepções das crianças sobre os ambientes naturais. A maioria das pesquisas tem como participantes crianças urbanas, mas também pudemos recolher informações acerca de investigações conduzidas com comunidades que vivem em ambientes naturais.

Conforme indicam estudos sobre a relação entre as pessoas e o ambiente, a criança, à medida que percebe o seu ambiente e interage com ele, torna-se capaz de ampliá-lo progressivamente, e de melhor compreender os diversos níveis e a complexidade que compõem sua paisagem (Chawla, 2002; Tuan, 1978). Nesta direção, muitas pesquisas que envolvem a utilização do desenho para a análise da percepção de crianças sobre os ambientes naturais partem do pressuposto de que a percepção ambiental é ampliada com o desenvolvimento infantil, ou seja, que o amadurecimento físico, psicológico e cognitivo da pessoa proporciona uma apreensão mais ampla e complexa do ambiente (Barraza, Ahumada, \& CejaAdame, 2006). O contexto, em seus aspectos históricos e culturais vivenciados como experiências pessoais, tem uma influência crucial na percepção das crianças sobre os ambientes naturais e seus elementos (Bossche, 2006; CroninJones, 2005; Lodge, 2007; Sinner, 2008).

De acordo com Barraza, Ahumada e CejaAdame (2006), os desenhos permitem o diagnóstico de conhecimentos do participante acerca de determinado tema ou fenômeno, porque sua produção estimula a recriação de conceitos e objetos. Outro pressuposto que orienta algumas investigações que envolvem crianças e ambientes naturais indica que as crianças se preocupam com a natureza nos planos emocional, cognitivo e ético (Barraza, Ahumada, \& Ceja-Adame, 2006; Kahn, 2002; Malone \& Tranter, 2003; Snaddon, Turner, \& Foster, 2008). Ou seja, as crianças seriam mais sensíveis que os mais velhos em relação aos problemas ambientais $e$ às mudanças necessárias para interações mais próambientais.

Independente do referencial teórico ou dos propósitos da investigação, os desenhos infantis são utilizados para fornecer informações acerca da percepção ambiental, do conhecimento ecológico e dos valores compartilhados por um determinado grupo ou comunidade. Entre as conclusões das pesquisas, foi consenso que o desenho é uma ferramenta adequada, e mesmo indicada para análise e avaliação da percepção das crianças sobre os ambientes naturais e os seres que os habitam. Esta adequação do desenho como instrumento de pesquisa junto a crianças é apontada por muitos investigadores, os quais destacam sua fácil aceitação, a suavização de uma situação assimétrica de teste com um recurso envolvente e relaxante e, no plano acadêmico, sua universalidade como linguagem infantil, capaz de ser decodificada e analisada por diversas disciplinas e em línguas distintas. Não obstante, o mais importante argumento consiste em considerar o desenho como uma imagem bastante próxima do que a criança percebe, conhece e valoriza acerca de determinado tema (Barraza, Ahumada, \& CejaAdame, 2006; Cronin-Jones, 2005; Schwarz, Sevegnani \& André, 2007; Snaddon, Turner \& Foster, 2008). Sua inclusão como estratégia metodológica em uma abordagem multimetológica triangular ou do tipo mosaico, é especialmente indicada quando se tem por objetivo uma apreciação abrangente e refinada das percepções ambientais (Gunther, Elali, \& Pinheiro, 2008).

\section{PAISAGENS DESENHADAS - AMBIENTES NATURAIS REVELADOS}

A seguir faremos uma breve apresentação de investigações que utilizaram o desenho para acessar a percepção ambiental infantil. Evidentemente, não realizamos uma síntese de 
todos os estudos já conduzidos, mas apenas dos mais recentes e daqueles que consideramos mais relevantes para os nossos próprios objetivos de pesquisa. Como assinalamos antes, as pesquisas são independentes e utilizam classificações e categorizações próprias, criadas em função do material produzido pelos participantes. Consequentemente, as comparações de ordem quantitativa ficam prejudicadas, pois os dados são coletados de modo autônomo, o que nos permite apenas observar tendências a serem posteriormente exploradas. Assim, destacamos apenas os dados passíveis de aproximação com mais de um dos estudos selecionados. Mais adiante discutiremos o caráter exploratório de nossa própria investigação, que busca concatenar nossas observações com aquelas realizadas anteriormente. Conforme Stebbins (2001), a exploração concatenada "se refere ao mesmo tempo a um processo de pesquisa e o conjunto resultante de estudos de campo que se encontram juntos e relacionados, como em uma cadeia principal constituída pelo acúmulo ou geração indutiva de teoria" (p. 12).

Em um estudo comparativo entre grupos infantis urbanos e rurais do Interior de Minas Gerais, Fandi e Melo (2000) analisaram desenhos de 60 alunos de oito e nove anos de idade cujas escolas estiveram envolvidas em um programa de educação ambiental. Foram realizadas coletas de desenhos antes e depois da execução do programa. As autoras verificaram um decréscimo no número de elementos desenhados entre a primeira e a segunda coleta e interpretaram esta diminuição como um avanço na compreensão dos temas ambientais. Com a escolha de poucos elementos para demonstrar seu conhecimento a criança é capaz de indicar com mais precisão uma representação adequada ao tema proposto. Conforme as pesquisadoras, as crianças possuem valores menos rígidos do que os adultos, portanto são mais sensíveis a mudanças estimuladas por intervenções ambientais.

Eloranta e Yli-Panula (2005) conduziram uma investigação qualitativa, descritiva e comparativa acerca dos animais representados nos desenhos infantis de paisagem. Esta pesquisa envolveu 946 crianças russas e finlandesas de sete a quinze anos de idade, alunos de escolas que participavam de um programa de educação ambiental conjunto entre os dois países. O objetivo principal foi $o$ de descrever a fauna representada nos desenhos, que tiveram como tema: "a paisagem que querem conservar". Os desenhos foram categorizados conforme a paisagem que preferencialmente representasse o ambiente natural, a que representasse o ambiente construído e ainda aquela que representasse o ambiente em que houvesse a presença humana. De modo geral, a natureza se impôs como a paisagem mais frequente, sendo retratada por $82 \%$ dos participantes. Os animais estiveram presentes em $31 \%$ dos desenhos, sendo em sua maioria aves, e mais especificamente avestraço, seguidas por mamíferos. Ao todo foram destacadas 25 espécies. Nas paisagens os animais se encontram adequadamente situados em seu ecossistema, o que revela uma boa compreensão das crianças acerca do hábitat retratado.

Barraza, Ahumada e Ceja-Adame (2006), utilizaram o desenho para inventariar as representações de biodiversidade entre crianças mexicanas com idades entre 11 e 13 anos. A partir de um concurso de desenhos com o tema "uma viagem pela natureza do México" foram selecionados 500 desenhos por estado, de um total de 1.500. A partir da análise dos desenhos, os pesquisadores concluíram que as crianças são capazes de desenhar adequadamente os elementos que fazem parte da biodiversidade e de representar as diferenças e interações entre as espécies (Barraza, Ahumada, \& Ceja-Adame, 2006). Conforme aumenta a idade da criança, observaram um aumento da diversidade biológica, do número de detalhes e de cenas que representavam interações entre as espécies e o ecossistema. Um alto percentual de crianças foi capaz de relacionar animais e plantas com seus respectivos ecossistemas. Ficou evidente também que os participantes desenhavam elementos bem característicos de sua localidade. Menos de $10 \%$ das crianças identificaram problemas ambientais, dos quais os mais representados foram: catástrofes ecológicas, morte de espécies, derrubadas de florestas, queimadas, lixo, resíduos tóxicos e contaminação da água e da atmosfera. Entre as crianças mais novas se encontrou mais a presença humana na natureza, e entre as mais velhas, uma maior quantidade de desenhos da categoria preocupações ambientais, denotando que estas últimas são mais sensíveis a estes problemas divulgados pela mídia. De uma forma geral, as crianças desenharam ambientes limpos 
de paisagens românticas. Para os investigadores, as representações da natureza produzidas pelas crianças são influenciadas tanto pelo contexto em que vivem como pelos conhecimentos escolares e por informações vindas de outras fontes, como, por exemplo, a mídia (Barraza, Ahumada, \& Ceja-Adame, 2006).

Martinho e Talamoni (2007) fizeram uma comparação entre representações gráficas do meio ambiente de 42 alunos da quarta série do Ensino Fundamental em duas escolas do Interior do Estado de São Paulo - uma rural e a uma urbana. Para este propósito foi conduzida uma pesquisa qualitativa com $\mathrm{o}$ apoio de dados quantitativos, por meio da análise de documentos e pesquisa de campo. Os objetivos específicos foram investigar as representações sobre o meio ambiente e analisar a multiplicidade de significados e noções que estes estudantes apresentaram, buscando identificar quais os aspectos sociais, padrões de comportamento familiar ou influências das informações veiculadas na mídia estariam presentes. Como ferramentas metodológicas foram empregadas observações, entrevistas semiestruturadas, desenhos e questionário. Duas tendências predominantes foram detectadas: uma que retratava os ecossistemas e uma que expressava problemas ambientais (Martinho \& Talamoni, 2007). Conforme os pesquisadores, os elementos da flora foram selecionados a partir de valores utilitaristas, com destaque para a vegetação frutífera. Na maioria dos casos os participantes não reconheceram a importância da vegetação nativa para a manutenção da biodiversidade. Observaram também uma maior presença de animais domésticos que de silvestres. Os alunos da escola rural desenharam espécies animais e vegetais regionais ou domesticadas, enquanto os alunos da escola urbana desenharam um ambiente natural alheio ao seu cotidiano, povoado por espécies exóticas, como, por exemplo, leões. Por outro lado, $70 \%$ dos desenhos estavam associados a uma visão naturalista do ambiente e $25 \%$ revelaram uma visão antropocêntrica. O homem esteve presente em $20 \%$ dos desenhos. A maioria dos desenhos (54\%) retratava florestas, rios, animais, plantas, enquanto os demais revelaram preocupação com poluição ambiental e a extinção de espécies. Para os investigadores, as representações encontradas, naturalistas e antropocêntricas, são influenciadas pela mídia, família e religião.

Schwarz, Sevegnani e André (2007) utilizaram desenhos para ter acesso às representações infantis da Mata Atlântica e de sua biodiversidade. A partir da análise de 395 desenhos de crianças urbanas de classe alta, com idades entre seis e catorze anos, foi possível apreciar os conhecimentos, observações, conceitos e competências em ciências dos participantes. O tema proposto foi "Mata Atlântica". Foram observados os elementos desenhados e o conjunto total desses elementos que caracterizavam um dado ecossistema, e realizada uma apreciação acerca do estado de conservação da Mata Atlântica. As explicações e recomendações escritas pelas crianças no verso do papel também foram consideradas. A média geral foi de 6,5 elementos desenhados por criança (um pouco superior entre as meninas). A paisagem de floresta, representada em $51,9 \%$ dos desenhos, pode ser relacionada com a Floresta Ombrófila Densa, em relevo acidentado; contudo, a maioria das árvores desenhadas não pôde ter sua espécie identificada $(92,7 \%)$ e apenas $7,3 \%$ tinham alguma característica que permitia sua identificação. As flores apareceram em 33,4\% das obras. As aves estiveram presentes em $52,2 \%$ dos desenhos, mas apenas $11,9 \%$ tinham uma forma específica definida, enquanto as demais são retratadas com linhas simples. Somente $7,6 \%$ dos desenhos representam a figura humana.

As crianças menores representaram a Mata Atlântica em bom estado de conservação em $74 \%$ dos desenhos, enquanto as maiores assim a representaram em $55 \%$. Os elementos da fauna tiveram menor frequência de representação, mas, quando presentes, predominaram os animais exóticos sobre a fauna brasileira. Foi também constatada uma forte interação entre animais e plantas, registrando a realidade de um ambiente que possui uma das maiores diversidades de animais e plantas do planeta, com fortes interações interespecíficas (Schwarz, Sevegnani, \& André, 2007).

Snaddon, Turner e Foster (2008) utilizaram o desenho para acessar o conhecimento acerca da uma da floresta tropical em um grupo de 76 crianças inglesas de três a oito anos de idade, alunos de uma escola primária de Cambridge. Em visita ao Museu Universitário de Zoologia, por ocasião de evento sobre a conservação das 
florestas, os estudantes participaram de concurso de desenho com o tema "A floresta tropical ideal". Foi efetuada a análise da frequência dos elementos naturais e a comparação do número relativo dos taxa (unidade de classificação dos seres vivos, ex. gênero, família, espécie) desenhados com a participação destes taxa na biomassa de uma porção de floresta na Amazônia Central e com o índice de biodiversidade global.

Os autores encontraram que a diferença de elementos do clima, da vegetação e de humanos não tem influência significativa da idade, mas o mesmo não pode ser dito acerca da frequência dos diferentes taxa, dado que os mais velhos desenham mais taxa diferentes e menor proporção de mamíferos e pássaros (Snaddon, Turner, \& Foster, 2008). De um modo geral, foi identificada uma visão sofisticada da floresta, com a incorporação de elementos do hábitat e uma ampla gama de espécies animais. Houve uma superrepresentação de mamíferos, aves e répteis e sub-representação de insetos e anelídeos, em relação tanto à sua real participação na biomassa como à diversidade de espécies na floresta tropical. A riqueza de detalhes desenhados por um grupo que nunca viu uma mata ao vivo é um indicador de que há uma consciência pública das qualidades e do valor da floresta para a humanidade e o planeta.

Elisei (2008) analisou o desenho de 200 crianças e adolescentes com idade entre dez e catorze anos, alunos do Ensino Fundamental de uma escola do interior do Estado de São Paulo, buscando identificar sua percepção ambiental. $\mathrm{O}$ pesquisador constatou um aumento da presença do homem no meio natural nos desenhos de adolescentes de até doze anos e seu declínio a partir dessa idade até os catorze nos, o que o levou a concluir que, com a falta de instrumentalização, o homem vai crescendo e se separando do meio natural. Ao mesmo tempo, foi possível identificar uma visão reducionista e simplista do ambiente, outra possível consequência do tratamento social dado ao tema ambiental (Elisei, 2008).

Pedrini, Costa e Ghilardi (2010) conduziram um estudo com 48 crianças e adolescentes com idade entre quatro e quinze anos, em situação de risco pessoal e social, em uma casa de acolhimento no Rio de Janeiro. O interesse dos autores foi a percepção ambiental e as representações sociais sobre o meio ambiente dos participantes. Os bens concretos se fizeram presentes em $94 \%$ dos desenhos, enquanto os naturais aparecem em $75 \%$. Ao todo, doze tipos de animais foram identificados nos desenhos. Chamou a atenção o grande número de representação de seres voadores, como as borboletas e aves. As arvores foram representadas principalmente sem os frutos $(63 \%)$, elemento que permitiria a sua identificação mais específica. As flores estão presentes em $34 \%$ do total. O sol foi o elemento mais representado, com $54,4 \%$ de frequência. Os investigadores concluíram que o meio ambiente percebido é aquele essencialmente visualizado (Pedrini, Costa, \& Ghilardi, 2010). O número expressivo de pássaros e borboletas é explicado em função de sua afluência às flores dos jardins que rodeiam a casa de acolhimento.

Antes de apresentar nossa própria investigação gostaríamos de destacar as tendências depreendidas da aproximação dos estudos aqui apresentados. Como já havíamos assinalado antes, parece consenso que o desenho é uma ferramenta adequada para apreensão da percepção infantil de meio ambiente, desde que complementado por outros instrumentos, em uma abordagem multimetodológica. O próprio tema meio ambiente é aparentemente de fácil identificação, assim como o tema paisagem, caracterizados ambos como cenários de predominância natural e pouca presença humana; porém a farta vegetação é genérica, pouco especificada, o que indicaria pouco conhecimento acerca da biodiversidade, já que a maioria dos estudos foi realizada com respondentes que vivem no contexto urbano e que o desenho impõe limitações à expressão do conhecimento da criança, que não se sente capaz de representá-lo graficamente. Estas informações são geralmente obtidas por meios verbais, reforçando ainda mais o valor de uma estratégia multimetodológica. Pudemos também observar certa preferência por ambientes ao ar livre quando se trata de meio ambiente, com a presença de animais, sobretudo aves e borboletas. Uma tendência evolutiva da percepção infantil também é indicada pelos estudos, pois crianças maiores desenham paisagens mais complexas e detalhadas do que as crianças menores. Por último, gostaríamos de destacar a ideia de que as crianças são mais sensíveis em sua percepção dos ambientes naturais, sentem-se 
envolvidas com os problemas ambientais e parecem mais suscetíveis à adoção de atitudes pró-ambientais.

\section{O ESTUDO DE VILA BRASIL - ASPECTOS DE MÉTODO}

Apresentamos a seguir nossa própria investigação, que teve por objetivo explorar e descrever as percepções infantis de ambientes naturais protegidos, especificamente do bioma de Mata Atlântica no Brasil (Profice, 2010). Nosso interesse foi conhecer as percepções ambientais de crianças que vivem em ambientes naturais protegidos. O contexto da pesquisa se encontra em Vila Brasil, vilarejo situado no entorno da Reserva Bioecológica de Uma, no Estado da Bahia (Rebio-Una). A região que contorna a Rebio-Una é classificada como zonatampão, uma área de segurança que deve ser protegida para suavizar o impacto humano nos ecossistemas da reserva. Estas zonas-tampão demandam profundas e constantes avaliações de seus níveis de biodiversidade e de suas atividades econômicas.

Os participantes foram 209 crianças com idade entre seis e onze anos, alunos das séries iniciais do Ensino Fundamental de sete escolas municipais situadas na zona-tampão da RebioUna. As crianças, além de frequentarem a escola, participam de atividades agrícolas de subsistência com os familiares, sobretudo no que envolve o plantio e a produção de farinha de mandioca. Os rios e córregos são explorados para pesca, coleta de água e lavagem de roupas e utensílios domésticos. Seja em atividades livres ou organizadas, as crianças passam a maior parte de seu dia em ambientes abertos, nem sempre sob a supervisão direta de adultos. Suas residências são modestas e muitas não dispõem de água corrente ou energia elétrica.

Para acessarmos a percepção ambiental das crianças participantes adotamos uma abordagem multimetodológica que utilizou 0 desenho, a entrevista, discussões em grupo e fotografias da paisagem local (Gunther, Elali, \& Pinheiro, 2008). Fizeram parte da equipe dois psicólogos ambientais, duas biólogas e educadoras ambientais, além das professoras das escolas, de estudantes universitários voluntários e outros colaboradores eventuais.

Em cada uma das dezoito salas de aula que visitamos foi feita a apresentação da equipe e a distribuição, para cada criança, de folhas de papel branco e uma caixa de lápis de cor. Inicialmente indicamos que eles poderiam desenhar livremente antes de nossa atividade propriamente dita, como uma forma de aclimatação e familiarização com a equipe e os materiais fornecidos. Após o desenho livre, que foi recolhido, entregamos uma folha no formato quadrado e solicitamos que desenhassem o meio ambiente à sua volta, a natureza do lugar onde vivem. À medida que terminavam suas produções, as crianças foram individualmente entrevistadas por um dos membros da equipe, previamente treinado, com o objetivo de conhecer as intenções e informações acerca do conteúdo dos desenhos, bem como a apreciação da criança acerca da atividade proposta. As falas explicativas e consideradas relevantes foram destacadas e transcritas.

A distribuição dos desenhos nas categorias, assim como as demais análises, foi realizada pela equipe de pesquisadores. Embora não tenhamos utilizado o cálculo da concordância entre juízes, as categorias foram intensa e extensivamente discutidas entre os membros da equipe, e eventuais discordâncias quanto a critérios foram discutidas e superadas antes da apuração definitiva das categorias nos desenhos. Para análise inventarial os elementos desenhados foram classificados em três categorias: Natural, Artificial e Humano. Na categoria Natural se encontram os elementos animais, vegetais, geográficos e celestes. $\mathrm{Na}$ categoria Artificial estão incluídas as edificações, como casas ou pontes e os meios de transporte. $\mathrm{Na}$ categoria Humano se encontram as representações de pessoas. Após esta primeira classificação os desenhos foram qualificados como paisagens: 1) naturais, quando havia somente $s$ presença de elementos naturais; 2) mistas, quando os elementos naturais entravam em composição com elementos artificiais e/ou humanos; e 3) artificiais, quando apareciam apenas elementos artificiais. Outra categoria foi criada para levar em conta a presença humana e suas atividades nas cenas desenhadas. As interações entre pessoas e ambientes foram classificadas como: 1) inexistentes, quando não havia pessoas na paisagem; 2) biocêntricas, quando a ação das pessoas desenhadas se orientava pelo interesse dos elementos naturais; 3) antropocêntricas, quando as ações se orientavam pelo interesse das pessoas; e 4) neutras, quando as pessoas em cena não 
estavam agindo ou quando sua ação não envolvia de forma intencional os elementos naturais em cena.

Decorrido um ano da coleta desses desenhos, retornamos a Vila Brasil para a realização dos grupos de discussão com duas turmas das dezoito em que haviam sido realizadas as sessões de desenho. Ao todo, os grupos envolveram quarenta e sete crianças. A discussão teve como ponto de partida a exibição na tela de um notebook dos desenhos produzidos no ano anterior. Quando perguntamos se alguém se lembrava do tema do desenho, o meio ambiente e a natureza foram citados por algumas crianças. As imagens foram comentadas e, juntamente com a equipe, buscamos levá-los a discutir quais eram aquelas árvores e animais e por que haviam sido desenhados. Por meio de anotações foi possível elencar as espécies animais e vegetais conhecidas pelas crianças, mesmo aquelas não desenhadas.

Durante as visitas a equipe tirou fotografias da paisagem do entorno das escolas com a finalidade não só de ilustrar o estudo exploratório, mas também de experimentar uma aproximação entre os desenhos das crianças e as fotografias.

\section{RESULTADOS E DISCUSSÃO}

Apenas 24 crianças, das 209, não consideraram a tarefa fácil, e somente nove afirmaram não ter gostado da atividade. Cada criança desenhou, em média, treze elementos, e não identificamos diferença expressiva entre meninos e meninas. Quando criamos os dois grupos, o das crianças com idade inferior a nove anos $(n=102)$ e o as crianças com idade superior a nove anos ( $n=107)$, constatamos médias de 11,7 e 14,2 elementos desenhados, respectivamente. Estes resultados coincidem com os de outras pesquisas que também observaram maior número de elementos e detalhes no desenho de crianças mais velhas, quando comparado com o das mais novas (Barraza et al., 2006; Cronin-Jones, 2005). Acreditamos também que a familiaridade com o tema tratado incide sobre a habilidade em representá-lo no desenho. Schwarz et al. (2007) obtiveram uma média de 6,5 elementos nos ambientes naturais desenhados por crianças urbanas, reforçando a ideia de que a média 13 obtida em nossa investigação pode ser atribuída ao fato de nossos participantes viverem e interagirem na paisagem natural retratada e por isso dominarem um maior repertório dos elementos e seres que a povoam.

Quanto ao tipo de paisagem, as mistas foram as mais frequentes (63\%). Ao comparar as categorias "tipos de paisagens (mistas e naturais)" não encontramos uma diferença significativa entre meninos e meninas ( $N=209$; $\left.X^{2}=0,995 ; g l=1 ; \alpha=0,318\right)$. O mesmo se deu na comparação das categorias tipos de paisagens (natural, humana e mista), não encontramos diferença significativa entre crianças menores e maiores de nove anos $\left(\mathrm{N}=209 ; \mathrm{X}^{2}=0,068 ; \mathrm{gl}=1\right.$; $\alpha=0,794$ ).

Os elementos da categoria Natural foram os mais desenhados pelas crianças e estiveram presentes em 205 dos 209 desenhos. Acreditamos que este resultado se deve tanto à predominância natural do ambiente em que essas crianças vivem como à orientação dada quando foram solicitadas a desenhar o meio ambiente e a natureza à sua volta. Como indicamos anteriormente, este resultado de dominância de aspectos naturais no meio ambiente também foi encontrado nos estudos de Barraza, Ahumada e Ceja-Adame (2006), Elisei (2008) e Eloranta e Yli-Panula (2005).

Nas paisagens desenhadas pelas crianças de Vila Brasil, $89 \%$ da vegetação são genéricas, ou seja, não representam uma determinada espécie. A predominância de tipos de árvores não especificados também foi encontrada em Schwarz, Sevegnani e André (2007) e em Pedrini, Costa e Ghilardi (2010). Os animais estão presentes em $61 \%$ dos desenhos, o que pode ser considerado expressivo em comparação com os dados de Eloranta e Yli-Panula (2005), em estes correspondem a 31\%, e Pedrini, Costa e Ghilardi (2010), em que correspondem a $40 \%$. Mais uma vez, o espaço de vida se revela crucial para a percepção ambiental e, consequentemente, para as representações gráficas que dela derivam. Dos animais desenhados pelas crianças de Vila Brasil, 92\% são silvestres e apenas $8 \%$ são domésticos. As aves estão em $80 \%$ dos desenhos. O número expressivo de aves, encontrado por quase todos os pesquisadores, pode ser explicado por dois fatores. O primeiro se refere à quantidade efetiva de aves na paisagem retratada, como no caso do entorno da Rebio-Uma; e o segundo 
fator, de ordem mais técnica e estética, impele as crianças a não deixarem espaços vazios em seus desenhos. O mesmo pode ser dito em relação à presença das flores (53\%), marcante na nossa e em outras investigações.

A média de elementos naturais geográficos como morros e rios foi de 0,93 por desenho; porém as crianças com menos de nove anos obtiveram uma média de 0,75 , enquanto as de idades superiores às destas obtiveram a média 1,11. Este resultado reforça a ideia acima discutida de que o domínio do espaço pela criança progride conforme seu desenvolvimento; quanto mais velha é a criança, mais ela é capaz de perceber e retratar organizações ambientais mais amplas, como vales e colinas. A presença humana, verificada em $25,8 \%$ dos desenhos, também foi expressiva quando comparada com a encontrada em outras investigações, sobretudo salientando-se a baixa densidade demográfica da região pesquisada. Martinho e Talamoni (2007) encontraram presença humana em $20 \%$ e Schwarz, Sevegnani e André (2007) em 7,6\%. Quando distribuímos os desenhos conforme as categorias criadas para apreciar a presença humana nas paisagens, obtivemos os seguintes dados: inexistente (não há pessoas na paisagem), 74,2\%; biocêntrica (a ação das pessoas desenhadas se orienta pelo interesse dos elementos naturais), 1,4\%; antropocêntrica (as ações são orientadas pelo interesse das pessoas), 2,9\%; e neutra (quando as pessoas em cena não estão agindo ou sua ação não envolve de forma intencional os elementos naturais em cena), 21,5\% Fica mais uma vez evidente a opção do grupo por não incluir pessoas em sua representação de meio ambiente, indicando uma possível influência antropocêntrica, segundo a qual os seres humanos não fazem parte da natureza, conforme foi levantado por Elisei (2008). Quando as pessoas se encontram nas paisagens são raramente retratadas em movimento ou ação, o que limitou bastante qualquer consideração quantitativa mais profunda. Aqui mais uma vez nos deparamos com uma limitação do desenho enquanto via de acesso à percepção ambiental dos participantes, o que torna incontornável sua complementação por outra ferramenta metodológica, como prevê a estratégia multimetodológica. A imobilidade das personagens nos desenhos classificados como de interação neutra não significa que as crianças não percebam a interatividade entre pessoas e ambientes, pois isto seria absurdo. A dificuldade em desenhar figuras humanas em ação pode orientar as opções da criança em uma direção mais estética, ou seja, com menor preocupação em retratar uma interação do que com a aparência das personagens e a harmonia do conjunto.

Pelas razões acima pontuadas, a apreciação de um desenho deve ser a de sempre compreender a narrativa da criança. Tivemos um bom exemplo no desenho do menino Raí, com dez anos: um homem caça um tatu enquanto outro passeia de helicóptero (figura 1). Este desenho foi classificado como antropocêntrico, porque o que está encenado é o homem armado carregando a caça, ou seja, o recurso natural está retratado a partir de sua utilidade e serventia para as pessoas. Quando foi entrevistado, Raí descreveu seus elementos: "várias árvores, flores, borboletas, cactos que tem do lado da minha casa, helicóptero, sol e um caçador com um tatu na mão". O nome dado ao desenho foi "A natureza é feliz", seguido da explicação "porque no final o caçador vai preso". Foi, então, apenas a partir a entrevista que ficou claro o posicionamento biocêntrico da criança, que, em sua narrativa, aplica uma punição ao caçador. Ao mesmo tempo, esta estória revelada pode indicar a intenção da criança de apresentar um quadro mais socialmente aceitável, o que não havia sido sua preocupação ao desenhar. Como no caso de Raí, os títulos dados aos desenhos refletem uma tonalidade afetiva positiva das paisagens produzidas pelas crianças. Podemos citar como outros exemplos de títulos "A floresta arco-íris", "A vida é linda", "Lugar bonito". Um exemplo de interação inexistente entre pessoas e ambientes naturais pode ser encontrado no desenho de Eduardo (figura 2), de apenas seis anos. Embora não tenha estabelecido conexões visíveis, já insinuou uma organização adequada para os elementos animais, vegetais e geográficos característicos da paisagem local. Na sua paisagem as árvores e as flores flutuam como as borboletas sobre um rio sem margens precisas. Quando questionado acerca das personagens em cena, respondeu - "a natureza é sem gente, só com animais". 
Figura 1. Raí, 10 anos. "A natureza é feliz".

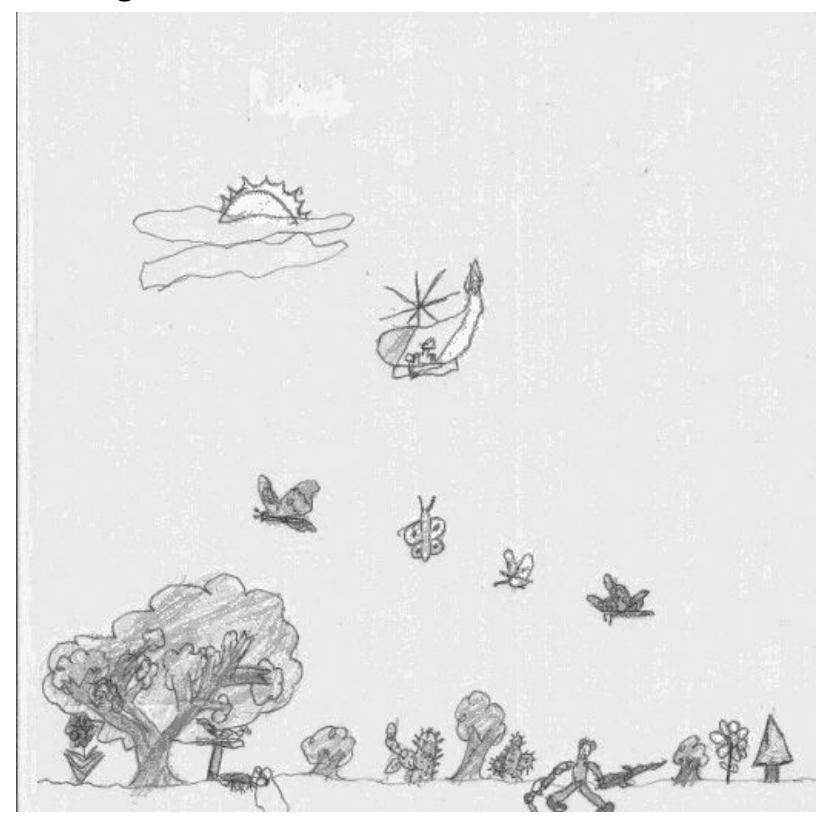

Figura 2. Eduardo, 6 anos. Sem título.

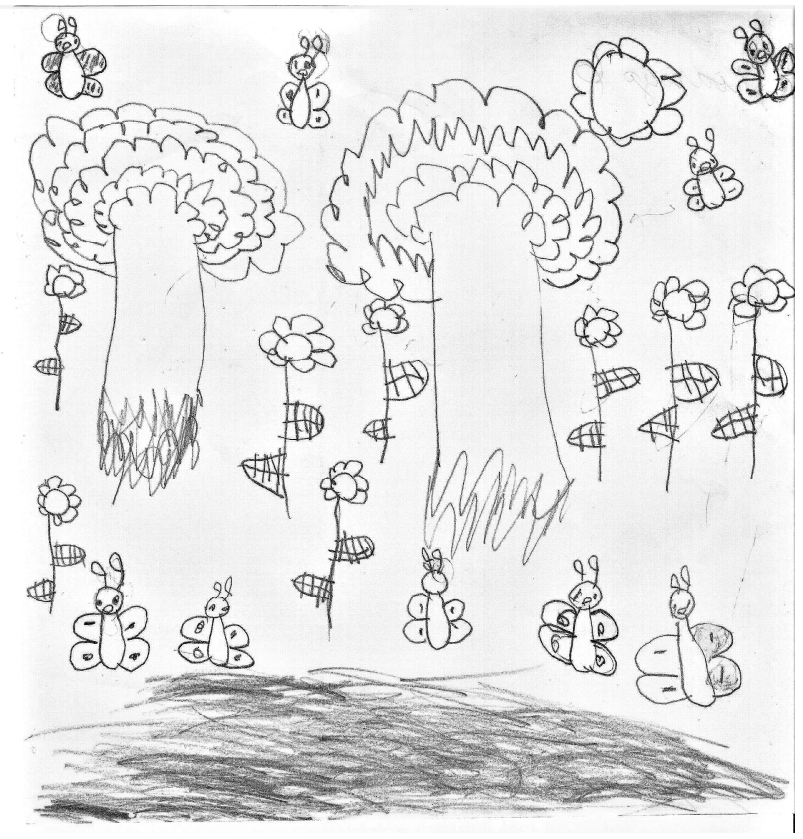

Os resultados encontrados por meio da articulação dos desenhos, das entrevistas, dos grupos de discussão e das fotografias nos permitiram delinear a percepção das crianças sobre o ambiente protegido em que vivem. A concatenação destas distintas fontes de informação com a literatura disponível nos permitiu conclusões que não seriam possíveis com a adoção de um único instrumento. As entrevistas nos permitiram apreciar o desenho por meio do olhar de quem o realizou, conduzindo nossa percepção para os elementos relevantes. De forma geral, foi possível destacar a proximidade entre a paisagem local - da vida dos participantes - e a paisagem desenhada por eles e ao mesmo tempo observar aspectos próprios do desenhar infantil que se manifestam em diferentes contextos culturais. As características marcantes do bioma Mata Atlântica se revelaram com clareza nos desenhos das crianças de Vila Brasil, por meio da predominância de espécies vegetais e pela presença significativa de aves e peixes, estes últimos sempre desenhados em rios ou cachoeiras. Chamou a atenção da equipe a ausência de fogo nos desenhos, já que queimadas são frequentes no entorno da reserva. Acreditamos que esta omissão possa ser atribuída ao desejo dos participantes de atender ao que consideram a expectativa dos pesquisadores.

Diferente de um retrato fiel do real, o desenho revelou um complexo arranjo do que a criança percebe e conhece e do que ela considera esteticamente adequado e se sente capaz de desenhar. Os aspectos cognitivos indicaram um conhecimento adequado dos elementos naturais do ambiente e das características determinantes da paisagem. Não obstante, a articulação destes elementos e aspectos naturais em uma compreensão mais complexa e ampliada da natureza foi pouco observada. Acreditamos que isto se deva, em parte, ao fato de que na faixa etária dos participantes a compreensão de sistemas naturais mais amplos não está ainda consolidada, mas também por limitações do ambiente escolar e comunitário que, dada sua precariedade, não oferecem oportunidades e inputs de informação que facilitem esta ampliação de perspectiva. Seria oportuno em uma próxima investigação descrever 0 repertório imagético disponibilizado pelas escolas e pelos livros didáticos.

Os aspectos valorativos da percepção ambiental tendem a ser antropocêntricos e utilitaristas. Os elementos naturais são valorizados em função do interesse das pessoas que deles se utilizam, sobretudo no que se refere ao seu uso alimentar. A partir desta visão, o ambiente natural deve ser preservado para que as pessoas possam desfrutar de seus recursos com segurança. Nos grupos de discussão surgiu a preocupação com a preservação do ambiente local, sobretudo no tocante à água e ao lixo. Acreditamos que este conhecimento advém das experiências interativas cotidianas com 0 
ambiente natural degradado, da influência dos programas de educação ambiental para professoras e também das informações fornecidas pelos meios de comunicação. Foi também possível perceber que 0 apego que manifestam pelo ambiente em que vivem é positivo. Interagir cotidianamente em ambientes naturais, estabelecer laços positivos com a natureza, conhecer seus elementos e processos e ser consciente de seus problemas são condições necessárias para que as pessoas desenvolvam atitudes preservacionistas; mas uma reflexão mais cautelosa, apoiada nas investigações precedentes, leva-nos a acreditar que estas condições são necessárias, mas ainda insuficientes.

\section{PERSPECTIVAS PARA PESQUISAS FUTURAS}

Além dos resultados acima discutidos, trazemos desta experiência algumas indicações de como pensar futuras investigações acerca da percepção que as crianças têm de ambientes naturais que incluam 0 desenho como ferramenta metodológica. Nesta direção, reforçamos a importância de observar, na história de vida do indivíduo, a evolução quantitativa e qualitativa dos desenhos do meio ambiente enquanto fonte de dados para a pesquisa comparativa e intercultural. Embora seja crescente o número de investigações sobre este tema, os dados raramente podem ser comparados, devido à falta de uniformidade no estabelecimento das faixas etárias, na definição dos temas desenhados, nas classes e categorias definidas, e na forma de quantificar os elementos. Apesar de encontrarmos muitos aspectos comparáveis, estas aproximações ainda se dão de forma superficial e inconsistente, lacuna a ser preenchida por estudos futuros.

Fica cada vez mais evidente a influência dos aspectos socioculturais na percepção ambiental dos ambientes naturais e, consequentemente, na forma como são desenhados. As diferenças encontradas nos estudos realizados entre os desenhos das crianças urbanas e os daquelas que vivem em ambientes naturais realizados nos compelem a explorar melhor este aspecto. Parece claro que o afastamento de ambientes naturais causado pela vivência em contextos urbanos faz com que as crianças conheçam menos os seres e processos da natureza, o que resulta em sua menor valorização e apreço, aspectos cruciais para o fomento de atitudes próambientais. Investigações futuras e intervenções no campo da educação ambiental devem levar em consideração a necessidade de reaproximação das crianças com ambientes naturais.

A abordagem multimétodos é, sem dúvida, a mais adequada quando se opta por utilizar o desenho para acessar a percepção ambiental de crianças. Essa abordagem ao mesmo amplia seu alcance como ferramenta metodológica e permite a compensação de suas limitações por meio de estratégias adicionais. No que se refere à apreciação de valores nas percepções ambientais reveladas no desenho, achamos adequada a busca por categorias naturalistas/biocêntricas ou utilitaristas/antropocêntricas como forma de subsidio para estudos ambientais, diagnósticos e ações na esfera da educação ambiental. A observação de problemas ambientais desenhados e suas soluções também podem indicar os caminhos mais adequados para a educação ambiental dos participantes.

Neste trabalho buscamos nos aproximar dos desafios teóricos e, sobretudo, dos metodológicos, de usar o desenho para conhecer a percepção de crianças sobre o ambiente por meio da identificação das principais tendências nos estudos recentes e de algumas direções pertinentes ao diálogo interdisciplinar e metodológico que caracteriza este campo. Acreditamos que, com 0 amadurecimento na adequação entre referências conceituais e métodos de pesquisa, será possível formular hipóteses e análises científicas mais promissoras, capazes de subsidiar ações que busquem reverter o distanciamento entre crianças e ambientes naturais nos planos afetivo, valorativo e cognitivo.

\section{REFERÊNCIAS}

Arbogast, K. L.; Kane, B. C. P.; Kirwan, J. L.; Hertel, B. R. (2009). Vegetation and outdoor recess time at elementary schools: What are the connections? Journal of Environmental Psychology 29, 450-456.

Barraza, L., Ahumada, H., \& Ceja-Adame, M. P. (2006). El dibujo como herramienta de análisis: conocimientos, percepciones y actitudes sobre la diversidad biológica de los niños en México. In R. Calixto (Org.), Educación ambiental para un futuro sostenible (pp. 271-282). Cidade do México: Universidad Pedagógica Nacional. 
Bossche, J. V. (2006). Dessine-moi ton monde. L'art enfantin dans plusieurs parties du monde. Sprimont: Mardaga.

Chawla, L. (2002). Spots of time: manifold ways of being in nature in childhood. In P. Kahn Jr., \& S. R. Kellert (Orgs.), Children and nature: psychological, sociocultural and evolutionary investigation (pp. 199225). Cambridge: Massachusetts Institute of Technology Press.

Cronin-Jones, L. L. (2005). Using drawings to assess student perceptions of schoolyard habitats: a case study of reform-based research in the United States. Canadian Journal of Environmental Education, 10, 225-240.

Elisei, M. G. M. (2008). Diagnóstico da percepção ambiental através do desenho infantil. Taubaté: Cabral Editora e Livraria Universitária.

Eloranta, V., \& Yli-Panula, E. (2005). Animals in the landscape drawings of Finnish and Russian young people - in the landscape they want to conserve. Nordina, 2, 5-17.

Fandi, A. C., \& Melo, C. (2000). Desenhos como instrumentos de avaliação de um programa de educação ambiental para alunos das zonas rural e urbana. Espaços da Escola, 37, 23-28.

Gunther, H., Elali, G. A., \& Pinheiro, J. Q. (2008). A abordagem multimétodos em Estudos PessoaAmbiente: características, definições e implicações. In J. Q. Pinheiro \& H. Gunther (Orgs.), Métodos de pesquisa nos estudos pessoa ambiente (pp. 369396). São Paulo: Casa do Psicólogo.

Kahn, P. H., Jr. (2002). Children's affiliations with nature: structure, development and the problem of environmental generational amnesia. In P. H. Kahn Jr. \& S. R. Kellert (Orgs.). Children and nature: psychological, sociocultural and evolutionary investigations (pp. 93-116). Cambridge: Massachusetts Institute of Technology Press.

Kellert, S. R. (2002). Experiencing nature: affective, cognitive, and evaluative development in children. In P. H. Kahn Jr. \& S. R. Kellert (Orgs.), Children and nature: psychological, sociocultural and evolutionary investigations (pp. 117-151). Cambridge: Massachusetts Institute of Technology Press.

Lodge, C. (2007). Regarding learning: Children's drawings of learning in the classroom. Learning Environment Research, 10, 145-156.
Malone, K., \& Tranter, P. (2003). Children's environmental learning and the use, design and management of school grounds. Children, Youth and Environments, 13(2). Obtido em 18/03/2013, de http://colorado.edu/journals/cye.

Martinho, L. R., \& Talamoni, J. L. B. (2007). Representações sobre meio ambiente de alunos da quarta série do ensino fundamental. Ciência \& Educação, 13(1), 1-13.

Pedrini, A., Costa, E. A., \& Ghilardi, N. (2010). Percepção ambiental de crianças e pré-adolescentes em vulnerabilidade social para projetos de educação ambiental. Ciência \& Educação, 16(1), 163-179.

Profice, C. C. (2010). Percepção ambiental de crianças em ambientes naturais protegidos. Tese de doutoramento não publicada, Universidade Federal do Rio Grande do Norte, Natal.

Schwarz, M. L., Sevegnani, L., \& André, P. (2007). Representações da mata atlântica e de sua biodiversidade por meio dos desenhos infantis. Ciência \& Educação, 13(3), 369-388.

Sinner, A. (2008). Landscapes of meaning: from childhood art to geographies of self as artist/researcher/teacher. Canadian Journal of Education, 31(11), 255-262.

Snaddon, J. L., Turner, E. C., \& Foster, W. A. (2008). Children's perceptions of rainforest biodiversity: which animals have the lion's share of environmental awareness? PlosOne, 3(7), 1-5.

Stebbins, R. A. (2001). Exploratory research in social sciences. Thousand Oaks: Sage.

Tuan, I. F. (1978). Children and the natural environment. In I. Altman \& J. F.Wohlwill (Orgs.), Human Behavior and Environment: Vol. 3. Children and the environment (pp. 5-32). Nova York: Plenum.

UNPFA (2011). Relatório sobre a Situação da População Mundial. Brasília: Fundo de População das Nações Unidas.

Christiana Cabicieri Profice: doutora em Psicologia pela Universidade Federal do Rio Grande do Norte, professora adjunta da Universidade Estadual de Santa Cruz

José de Queiroz Pinheiro: doutor em Psicologia Ambiental pela University of Tucson (EUA), professor titular na Universidade Federal do Rio Grande do Norte.

Ana Cláudia Fandi: mestre em Conservação e Biodiversidade para lideranças do sul da Bahia, IPÊ, membro do Instituto de Estudos Socioambientais da Bahia.

Ana Roberta Gomes: mestre em Ecologia e Recursos Naturais pelo Programa de Pós-Graduação da Universidade Federal de São Carlos, membro do Instituto de Estudos Socioambientais da Bahia. 